\title{
Interação entre genótipos e ambientes e implicações em ganhos com seleção em trigo
}

\author{
Adeliano Cargnin $^{(1)}$, Moacil Alves de Souza(2), Pedro Crescêncio Souza Carneiro(3) e Valdinei Sofiatti(2)
}

\begin{abstract}
(1)Universidade Federal de Viçosa (UFV), Dep. de Genética e Melhoramento, Av. P.H. Rolfs, s/no, CEP $36571-000$ Viçosa, MG. E-mail: adelianoc@hotmail.com (2)UFV, Dep. de Fitotecnia. E-mail: moacil@ufv.br, sufiatti@vicosa.ufv.br (3)UFV, Dep. de Biologia. E-mail: carneiro@ufv.br
\end{abstract}

Resumo - O objetivo deste trabalho foi quantificar o componente da interação genótipos x ambientes e avaliar seus reflexos no progresso genético com diferentes critérios de seleção de linhagens de trigo adaptadas às condições do Brasil Central. Foram avaliadas 240 famílias $\mathrm{F}_{2: 4}$ oriundas de oito populações segregantes de trigo. Os experimentos foram conduzidos em campo, com semeaduras realizadas no verão e no inverno, em 2004. Foi utilizado o delineamento em látice com duas repetições. Avaliaram-se os caracteres espigamento, altura de planta, massa do grão e produtividade de grãos. Realizou-se a decomposição da interação genótipos x ambientes e foram estimados os ganhos com a seleção nos dois ambientes. O grau de tolerância ao calor foi determinado com base em dois índices. A porcentagem da interação de natureza complexa foi maior do que a simples, e ganhos com seleção indireta, em um ambiente, não foram eficientes, principalmente quanto à produtividade de grãos. Apesar da interação genótipos $\mathrm{x}$ ambientes, o uso do índice de tolerância ao calor com base na regressão permite detectar genótipos produtivos sob condição de estresse de calor, pela melhoria da adaptabilidade dos genótipos a esse ambiente, sem alterar o comportamento desses genótipos em condições favoráveis.

Termos para indexação: Triticum aestivum, ganho genético, critério de seleção, adaptabilidade.

\section{Genotypes and environments interaction and its implication in gain with wheat selection}

\begin{abstract}
The objective of this work was to quantify the component of the genotypes $x$ environments interaction, as well as to evaluate its reflexes on the genetic progress with different selection criteria for those wheat lines adapted to the Brazilian midland conditions. Two hundred and forty $\mathrm{F}_{2: 4}$ families descending from eight segregant populations of wheat were evaluated. Experiments were conducted under field conditions, and sowings were accomplished in the summer and winter, 2004. The lattice design was used with two replicates. The following characters were evaluated: earing, plant height, grain weight, and grain yield. Decomposition of the genotypes $\mathrm{x}$ environments interaction was performed, and the gains with selection in both environments were estimated. The determination of the tolerance level to the heat was based on two indexes. The percentage of the complexnature interaction was higher than the simple one, whereas the gains with indirect selection in an environment were not efficient, mainly for grain yield. Although the genotypes x environments interaction, use of the tolerance index to the heat based on regression allows detecting the productive genotypes under heat stress by the improvement of the genotype adaptability to this environment, without changing these genotypes' behavior under favorable conditions.

Index terms: Triticum aestivum, genetic gains, selection criterion, adaptability.
\end{abstract}

\section{Introdução}

Por muitos anos, a cultura do trigo localizou-se predominantemente na zona de clima temperado, estendendo-se do Rio Grande do Sul até o sul do Paraná. Muitos pesquisadores julgavam essa região a mais adequada para a produção comercial desse cereal. Desde a década de 70, no entanto, a cultura do trigo tem-se expandido para o Centro-Oeste brasileiro, sendo cultivada em solos cobertos com vegetação de cerrado, e tem-se mostrado bastante promissora, com produtividades superiores a $7.000 \mathrm{~kg} \mathrm{ha}^{-1}$, em condições de cultivo comercial (Souza, 1999).

A diversidade de áreas de cultivo constitui uma solução para diminuir a variação na produção total decorrente de adversidades climáticas. Segundo Souza \& Ramalho (2001), 
o cultivo dessa gramínea é uma opção para rotação de culturas, necessária para manter produtividades elevadas das culturas de verão na Região do Brasil Central.

Pode-se realizar semeadura no final do verão, quando ainda há precipitações pluviais, o que contribui com a redução do custo de produção da lavoura. Porém, de acordo com Souza \& Ramalho (2001), neste caso, o excesso de calor, associado às deficiências hídricas periódicas, constitui o principal fator de redução do potencial produtivo dessa cultura.

A seleção e a recomendação de genótipos mais produtivos são objetivos básicos dos programas de melhoramento genético de qualquer espécie cultivada. O processo de seleção é, freqüentemente, realizado pelo desempenho dos genótipos em diferentes ambientes (ano, local, época de semeadura). Contudo, a decisão de lançamento de novas cultivares normalmente é dificultada pela ocorrência da interação genótipos $\mathrm{x}$ ambientes (Carvalho et al., 2002). Considerando o caráter produtividade de grãos, o fenótipo é a expressão da constituição genética do genótipo, do efeito de ambiente e da interação dos genótipos com ambientes.

A existência da interação genótipos $\mathrm{x}$ ambientes, para Cruz \& Regazzi (1997), está associada a dois fatores. O primeiro, denominado simples, é proporcionado pela diferença entre genótipos; o segundo, denominado complexo, é dado pela ausência de correlação entre os genótipos. A interação genótipos $x$ ambientes reduz a correlação entre o fenótipo e o genótipo. A correlação baixa indica que o genótipo superior em um ambiente, normalmente, não terá o mesmo desempenho em outro ambiente. A seleção com base no componente da interação genótipos $\mathrm{x}$ ambientes pode estar eliminando constituições genéticas altamente ajustadas a ambientes específicos.

A interação genótipos $\mathrm{x}$ ambientes não interfere apenas na recomendação de cultivares, mas também dificulta o trabalho do melhorista, que precisa adotar critérios diferenciados para selecionar genótipos superiores e usar métodos alternativos de identificação de material de alto potencial genético (Cruz \& Regazzi, 1997). Sendo assim, o componente da interação genótipos x ambientes está altamente relacionado com a cultura do trigo cultivado em ambientes distintos ou com semeadura em épocas diferentes.

O objetivo deste trabalho foi quantificar o componente da interação genótipos $\mathrm{x}$ ambientes e avaliar seus reflexos na predição do ganho genético com diferentes critérios de seleção de linhagens de trigo adaptadas às condições do Brasil Central.

\section{Material e Métodos}

Dois experimentos foram conduzidos em campo, em 2004, em duas épocas de semeadura (ambientes), na Estação Experimental de Coimbra, pertencente à Universidade Federal de Viçosa (UFV), localizada no Município de Coimbra, MG, na latitude de $20^{\circ} 45$ 'S, longitude de $42^{\circ} 51^{\prime} \mathrm{W}$ e altitude de $720 \mathrm{~m}$.

Foram avaliadas 240 famílias $\mathrm{F}_{2: 4}$ oriundas de oito populações dos seguintes cruzamentos: BH1146 x BR24, BR24 x Aliança, Aliança x EP93541, EP93541 x CPAC9662, CPAC9662 x IVI931009, IVI931009 x BRS207, BRS207 x Anahuac, Anahuac x BH1146, segundo esquema de dialelo circulante, de acordo com Bearzoti (1997).

A primeira semeadura foi realizada no dia 30 de janeiro (verão - condição de estresse), quando predominam temperaturas elevadas, várias horas por dia acima de $25^{\circ} \mathrm{C}$, durante o ciclo da cultura. A segunda semeadura foi efetuada em 2 de maio (inverno condição favorável), quando ocorrem temperaturas mais amenas (grande parte do dia próxima ou abaixo de $20^{\circ} \mathrm{C}$ ) durante a maior parte do ciclo da cultura.

As práticas culturais foram uniformes, nos dois experimentos, a fim de minimizar a influência de fatores bióticos ou abióticos. Ambos os experimentos foram irrigados, sempre que necessário.

A análise do solo foi feita no Laboratório de Análises de Solos da UFV. A adubação foi feita com base nos resultados dessa análise, aplicando-se $250 \mathrm{~kg} \mathrm{ha}^{-1}$ da fórmula 8-28-16, no sulco de semeadura, e $50 \mathrm{~kg} \mathrm{ha}^{-1}$ de N em cobertura, no início do perfilhamento. Os demais tratos culturais foram realizados de acordo com as recomendações técnicas para a cultura do trigo (Reunião da Comissão Centro Brasileira de Pesquisa de Trigo, 2003).

As 240 famílias e os oito genitores foram avaliados por meio do delineamento em látice com duas repetições. Foram utilizados mais oito genótipos de trigo, a fim de completar o látice. Cada parcela foi constituída de três linhas de 3,0 m de comprimento, no espaçamento de 0,3 m entrelinhas, utilizando-se 65 sementes aptas por metro, conferindo área útil de $2,7 \mathrm{~m}^{2}$. Foram avaliados os seguintes caracteres agronômicos: espigamento (dias), altura de planta (cm), massa do grão (mg por grão) e produtividade de grãos (g por parcela).

Depois das análises de variância individual, foi verificada a homogeneidade das variâncias residuais pelo 
teste de F máximo, que considera as variâncias residuais homogêneas quando a relação entre os quadrados médios residuais não ultrapassa o valor 7 . Constatada a homogeneidade das variâncias residuais, procedeu-se à análise de variância conjunta. O componente de variação da interação genótipos x ambientes (época de semeadura) foi quantificado considerando-se o efeito de genótipos aleatório e o de ambiente fixo, conforme Cruz \& Regazzi (1997), e estimada a decomposição do quadrado médio da interação em partes simples e complexa, utilizando-se a expressão proposta por Cruz \& Castoldi (1991).

Os ganhos obtidos pela seleção direta praticada em cada ambiente foram estimados pela expressão $\mathrm{GS}=\mathrm{DS}_{\mathrm{i}} \mathrm{h}_{\mathrm{i}}^{2}$, em que $\mathrm{GS}_{\mathrm{i}}$ é o ganho com seleção direta praticada no ambiente i; $\mathrm{DS}_{\mathrm{i}}$ é o diferencial de seleção com base nos indivíduos de melhor desempenho no ambiente $\mathrm{i}$; e $\mathrm{h}_{\mathrm{i}}^{2}$ é a herdabilidade do caráter no ambiente i. Os ganhos obtidos com a resposta indireta à seleção, realizada nos ambientes de verão e inverno, foram calculados por meio da fórmula $G S_{i(j)}=D S_{i(j)} h_{i}^{2}$, em que $\mathrm{GS}_{\mathrm{i}(\mathrm{j})}$ é o ganho no ambiente $\mathrm{i}$, com seleção baseada no ambiente $\mathrm{j}$; DS $\mathrm{i}_{\mathrm{i}(\mathrm{j})}$ é o diferencial de seleção no ambiente i, no qual os indivíduos selecionados são os de melhor desempenho no ambiente $\mathrm{j}$; e $\mathrm{h}_{\mathrm{i}}^{2}$ é a herdabilidade do caráter no ambiente i.

A fim de quantificar o grau de tolerância ao calor das progênies avaliadas no verão em relação ao inverno, e de se estabelecer uma combinação para a seleção simultânea entre as duas épocas de semeadura, foram calculados dois índices.

O primeiro foi o índice de tolerância ao calor (ITC 1 ) segundo a fórmula de Fischer \& Mauer (1978): $\mathrm{ITC}_{1}=\left(1-\mathrm{Y} / \mathrm{Y}_{\mathrm{P}}\right) / \mathrm{D}$, em que $\mathrm{Y}$ e $\mathrm{Y}_{\mathrm{P}}$ são as médias de cada progênie nos ambientes de verão e inverno, respectivamente; $\mathrm{D}$ (intensidade do estresse) é igual a $\left(1-X / X_{P}\right)$, em que $X$ é a média de todas as progênies no ambiente de verão, e $\mathrm{X}_{\mathrm{P}}$ é a média de todas as progênies no ambiente de inverno. De acordo com esses autores, as progênies são classificadas como altamente tolerante $\left(\right.$ ITC $_{1} \leq 0,50$ ), moderadamente tolerante $\left(0,50<\mathrm{ITC}_{1} \leq 1,00\right)$ e suscetível $\left(\mathrm{ITC}_{1}>1,00\right)$ à alta temperatura.

O segundo foi o índice de tolerância ao calor $\left(\mathrm{ITC}_{2}\right)$ de acordo com Coelho (1995), definido como o desvio do valor observado para a produtividade de um dado genótipo, sob condições de estresse, e o estimado pela equação de regressão linear que relaciona as produti- vidades das progênies sob condição de estresse e sob condição favorável, ou seja: $\operatorname{ITC}_{2}=\bar{Y}_{1.11}-\left(a+b \bar{Y}_{2.11}\right)$, em que $\bar{Y}_{1.1}$ é a média da progênie 1 na condição de estresse de calor; $\bar{Y}_{2 . .1}$ é a média da progênie 1 na condição favorável; a é o coeficiente linear da regressão entre as médias das progênies nas condições de estresse e favorável; e b é o coeficiente angular da regressão entre as médias das progênies nas condições de estresse e favorável.

Em todos os casos, a intensidade de seleção utilizada foi de $20 \%$. Todas as análises foram procedidas com o auxílio do programa computacional Genes (Cruz, 2001).

\section{Resultados e Discussão}

As análises de variância individuais em relação ao espigamento, à altura de planta, à massa do grão e à produtividade de grãos, nas duas épocas de semeadura, revelaram que os efeitos de genótipos apresentaram variações altamente significativas $(p \leq 0,01)$. Os coeficientes de variação dos caracteres oscilaram entre 2,63 (espigamento) e 12,67\% (produtividade de grãos), conferindo boa precisão aos experimentos, os quais, segundo Lúcio et al. (1999), são classificados como baixo a médio, respectivamente, sendo considerados habituais para ensaios agrícolas.

Uma vez verificada a homogeneidade das variâncias residuais pelo teste de $\mathrm{F}$ máximo, entre as duas épocas de semeaduras, cujos valores das relações foram 1,18, 1,38, 1,21 e 4,24 em relação ao espigamento, à altura de planta, à massa do grão e à produtividade de grãos, respectivamente, realizou-se a análise de variância conjunta dos experimentos. Pelo teste F foi possível verificar efeito significativo de genótipos, ambientes (época de semeadura) e também da interação genótipos x ambientes, quanto aos quatros caracteres. Os coeficientes de variação para essa análise também proporcionaram boa confiabilidade aos dados (Tabela 1).

Os quadrados médios para o efeito de época de semeadura (ambiente) foram os mais importantes, apresentando alta magnitude em todos os caracteres. Por sua vez, a magnitude da interação genótipos $\mathrm{x}$ ambientes também apresentou grandeza significativa quanto aos quadrados médios, principalmente para o caráter produtividade de grãos (Tabela 1). Isto indica que os genótipos apresentam respostas diferenciadas, quando submetidos a ambientes distintos, que, neste caso, expressa comportamentos diferenciados de tolerância ao calor. 
O caráter produtividade de grãos foi o mais influenciado pelo efeito da interação genótipos $\mathrm{x}$ ambientes, enquanto nos demais caracteres o efeito de genótipos foi mais relevante que o da interação (Tabela 2).

Segundo Falconer \& Mackay (1996), o caráter produtividade de grãos é governado por vários genes de pequeno efeito sobre o fenótipo, classificando esse caráter como quantitativo, ou seja, existe forte influência do ambiente na expressão desse caráter.

A parte complexa da interação genótipos x ambientes é dada pela falta de correlação entre fenótipo, genótipo e os desvios do ambiente. Coeficiente de correlação fenotípica baixo indica que o genótipo superior em um ambiente não terá, normalmente, o mesmo desempenho em outro ambiente. Segundo Cruz \& Regazzi (1997), quando há predominância da parte complexa da interação, o trabalho do melhorista fica dificultado.

A resposta diferenciada dos genótipos de trigo aos diferentes ambientes está de acordo com os conceitos de interação genótipos $\mathrm{x}$ ambientes citados por alguns autores (Ramalho et al., 1993; Borém, 1997; Cruz \& Regazzi, 1997), os quais relatam a importância da interação para o melhoramento, pois há possibilidades de os melhores genótipos em um ambiente não o serem em outro. Isto torna mais difícil a seleção ou a recomendação desses genótipos para o cultivo nos dois ambientes. Por sua vez, coeficiente de correlação próximo a zero não implica falta de associação entre duas variáveis; apenas reflete a ausência da relação linear entre estas variáveis (Cruz \& Regazzi, 1997).

A interação entre as duas épocas de semeadura foi predominantemente complexa e, conseqüentemente, proporciona dificuldade no processo de seleção (Tabela 2). A produtividade de grãos apresentou a maior porcentagem da parte complexa da interação genótipos $\mathrm{x}$ ambientes (73,84\%). Este resultado foi causado, principalmente, pela ausência de correlação linear fenotípica $(r=-0,0628)$, apesar de haver correlação linear genotípica, porém, de baixa magnitude $(\mathrm{r}=0,4745)$, entre as duas épocas de semeadura.

Em relação à altura de plantas, observou-se a menor porcentagem da parte complexa da interação $(46,34 \%)$ e também a maior estimativa de correlação fenotípica e genotípica entre ambientes. De modo geral, os resulta-

Tabela 1. Análise de variância conjunta em relação à altura de plantas (AP), ao espigamento (ESP), à massa do grão (MG) e à produtividade de grãos (PROD) em famílias de trigo.

\begin{tabular}{lccccc}
\hline Fonte de variação & GL & \multicolumn{4}{c}{ Quadrados médios } \\
\cline { 2 - 6 } & & AP $(\mathrm{cm})$ & ESP (dias) & MG (mg grão $\left.{ }^{-1}\right)$ & PROD $\left(\mathrm{g}\right.$ parcela $\left.{ }^{-1}\right)$ \\
\hline Genótipo (G) & 255 & $355,38^{* *}$ & $32,18^{* *}$ & $32,06^{* *}$ & $63.770,56^{* *}$ \\
Época (E) & 1 & $363.006,25^{* *}$ & $43.160,06^{* *}$ & $37.194,75^{* *}$ & $40.998 .717,40^{* *}$ \\
Gx E & 255 & $80,97^{* *}$ & $11,95^{* *}$ & $9,06^{* *}$ & $70.937,67^{* *}$ \\
Erro Efetivo Médio & 450 & 22,21 & 2,72 & 3,48 & $7.072,24$ \\
\hline CV $(\%)$ & & 13,05 & 4,31 & 5,24 & 3,08 \\
\hline
\end{tabular}

**Significativo a $1 \%$ de probabilidade pelo teste $\mathrm{F}$.

Tabela 2. Estimativa dos componentes de variância genotípica $\left(\hat{\sigma}_{g}^{2}\right)$ e da interação genótipos x ambientes $\left(\hat{\sigma}_{g a}^{2}\right)$, correlações entre os ambientes e porcentuais da parte simples e complexa da interação em relação ao espigamento (ESP), à altura de plantas (AP), à massa do grão (MG) e à produtividade de grãos (PROD) de 240 famílias de trigo.

\begin{tabular}{lcccc}
\hline Parâmetro & \multicolumn{3}{c}{ Caracteres } \\
\cline { 2 - 5 } & ESP (dias) & AP $(\mathrm{cm})$ & MG $\left(\mathrm{mg} \mathrm{grão}^{-1}\right)$ & PROD $\left(\mathrm{g} \mathrm{parcela}^{-1}\right)$ \\
\hline $\begin{array}{l}\text { Variância } \\
\hat{\sigma}_{\mathrm{g}}^{2}\end{array}$ & 7,19 & 78,55 & 7,06 & $14.268,89$ \\
$\hat{\sigma}_{\mathrm{ga}}^{2}$ & 2,18 & 11,91 & 1,30 & $15.800,60$ \\
\hline Correlação & & & \\
$\quad$ Fenotípica & $0,4559^{* *}$ & $0,6874^{* *}$ & $0,5746^{* *}$ & $-0,0628^{\mathrm{n}}$ \\
$\quad$ Genotípica & $0,7670^{* *}$ & $0,8684^{* *}$ & $0,8444^{* *}$ & $0,4745^{*}$ \\
\hline Parte da interação (\%) & & & \\
$\quad$ Complexa & 73,12 & 46,34 & 64,13 & 73,84 \\
$\quad$ Simples & 26,88 & 53,66 & 35,87 & 26,16 \\
\hline
\end{tabular}

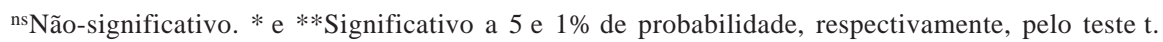


dos indicam a participação da interação complexa em todos os caracteres, evidenciando, assim, a maior dificuldade na seleção de genótipos superiores, para as duas épocas de semeadura.

Os ganhos alcançados pela seleção direta foram sempre superiores à resposta indireta, evidenciando a influência da interação genótipos $\mathrm{x}$ ambientes quando do ganho genético num ambiente (j) e resposta da seleção no outro ambiente (j’) (Tabela 3). Este valor da resposta direta é, em parte, conseqüência da própria expressão utilizada para sua estimativa (Cruz \& Regazzi, 1997).

A produtividade de grãos evidenciou resposta correlacionada inferior e de sinal contrário às estimativas dos demais caracteres, que apesar de terem as estimativas de ganhos com respostas correlacionadas reduzidas, não apresentam ganhos negativos. Este fato pode resultar da ausência de correlação linear entre as duas épocas de semeadura quanto à produtividade de grãos.

Em trabalhos com três épocas de semeadura com a cultura do feijão, Coimbra et al. (1999) também encontraram resposta correlacionada inferior e de sinal contrário entre um par de ambientes para produtividade de grãos. Segundo eles, a existência de correlação negativa entre este par de ambientes explica o fato.

A produtividade de grãos é a característica mais importante em um programa de melhoramento genético.

Tabela 3. Coeficientes de herdabilidade $\left(\mathrm{h}^{2}\right)$ e ganhos genéticos pela seleção direta e indireta nos ambientes de verão e inverno em caracteres de 240 famílias de trigo.

\begin{tabular}{|c|c|c|c|c|c|}
\hline \multirow[t]{2}{*}{ Caracteres } & \multirow[t]{2}{*}{$\begin{array}{l}\text { Seleção no } \\
\text { ambiente }\end{array}$} & \multirow[t]{2}{*}{$h^{2}$} & \multicolumn{2}{|c|}{$\begin{array}{l}\text { Resposta no } \\
\text { ambiente }^{(1)}\end{array}$} & \multirow[t]{2}{*}{ Total } \\
\hline & & & Verão & Inverno & \\
\hline \multirow[t]{2}{*}{$\begin{array}{l}\text { Espigamento } \\
\text { (dias) }\end{array}$} & Verão & 0,835 & $\begin{array}{c}4,02 \\
(8,54)\end{array}$ & $\begin{array}{c}2,10 \\
(4,46)\end{array}$ & 13,00 \\
\hline & Inverno & 0,869 & $\begin{array}{c}2,32 \\
(3,86)\end{array}$ & $\begin{array}{c}3,95 \\
(6,58) \\
\end{array}$ & 10,44 \\
\hline \multirow[t]{2}{*}{$\begin{array}{l}\text { Altura de planta } \\
(\mathrm{cm})\end{array}$} & Verão & 0,704 & $\begin{array}{c}7,57 \\
(10,65)\end{array}$ & $\begin{array}{c}5,46 \\
(7,68)\end{array}$ & 18,33 \\
\hline & Inverno & 0,928 & $\begin{array}{c}9,98 \\
(9,18)\end{array}$ & $\begin{array}{c}15,31 \\
(14,08) \\
\end{array}$ & 23,26 \\
\hline \multirow[t]{2}{*}{$\begin{array}{l}\text { Massa do grão } \\
\left(\mathrm{mg} \mathrm{grão}^{-1}\right)\end{array}$} & Verão & 0,758 & $\begin{array}{c}3,05 \\
(8,18) \\
\end{array}$ & $\begin{array}{c}1,80 \\
(4,83) \\
\end{array}$ & 13,01 \\
\hline & Inverno & 0,867 & $\begin{array}{c}2,89 \\
(5,86) \\
\end{array}$ & $\begin{array}{c}4,43 \\
(8,98) \\
\end{array}$ & 14,84 \\
\hline \multirow{2}{*}{$\begin{array}{l}\text { Produtividade de } \\
\text { grãos } \\
\left(\mathrm{g} \text { parcela }{ }^{-1}\right)\end{array}$} & Verão & 0,843 & $\begin{array}{l}131,67 \\
(29,62)\end{array}$ & $\begin{array}{l}-18,78 \\
(-4,22) \\
\end{array}$ & 25,40 \\
\hline & Inverno & 0,891 & $\begin{array}{c}-8,30 \\
(-0,98)\end{array}$ & $\begin{array}{l}308,73 \\
(36,55) \\
\end{array}$ & 35,57 \\
\hline
\end{tabular}

${ }^{(1)}$ Valores entre parênteses referem-se aos ganhos porcentuais.
Dessa forma, como estratégia alternativa de identificação dos genótipos desejados, foram calculados índices de tolerância ao calor, para quantificar a capacidade dos genótipos de apresentar produtividades elevadas em condições de estresse (verão), sem reduzir suas produtividades no inverno.

O índice de tolerância ao calor ( ITC $_{1}$ ), que considera como tolerante o genótipo com índice menor que 0,5 , proporcionou, com seleção dos 50 melhores índices (menores valores), ganho para o ambiente de verão de $14,6 \%$. A resposta no ambiente de inverno com a seleção dessas mesmas famílias é de $-27,6 \%$, ou seja, aumentar a produtividade de grãos no verão com a seleção baseada nesse índice acarreta forte redução da produtividade no inverno. Na seleção com base nos 50 piores índices (maiores valores), ou seja, índices com valores maiores que 1 , considerados suscetíveis ao calor, os ganhos no ambiente de inverno foram satisfatórios, chegando a $28,5 \%$. Entretanto, no ambiente de verão a resposta foi inferior e de sinal contrário (-17,6\%).

Quanto ao índice de tolerância (ITC 2$)$, a seleção das famílias com os 50 melhores índices, ou seja, aquelas cujos índices apresentam os maiores valores, proporcionou elevado ganho para o ambiente de verão (28,5\%), sem afetar muito a produtividade média das progênies no ambiente de inverno (Tabela 4). Por sua vez, na seleção das 50 famílias com os piores índices para o ambiente de inverno obteve-se $-1,2 \%$ de ganho, o que não altera o comportamento médio das progênies

Tabela 4. Ganhos por seleção (GS) direta (verão) e indireta (inverno) nos ambientes de inverno e verão, quanto ao caráter produtividade de grãos de trigo, com base nos índices ITC $_{1}$ $\mathrm{e} \mathrm{ITC}_{2}{ }^{(1)}$.

\begin{tabular}{|c|c|c|c|c|c|}
\hline $\begin{array}{l}\text { Índices } \\
\text { selecionados }\end{array}$ & Época & $\mathrm{h}^{2}$ & $\begin{array}{c}\overline{\mathrm{X}}_{\mathrm{O}} \\
\left(\mathrm{g} \text { parcela }^{-1}\right.\end{array}$ & $\begin{array}{c}\overline{\mathrm{X}}_{\mathrm{s}} \\
\left.\left(\mathrm{g}_{\text {parcela }}\right)^{-1}\right)\end{array}$ & $\begin{array}{c}\text { GS } \\
\left(\text { g parcela }^{-1}\right)\end{array}$ \\
\hline & & & & $\mathrm{TC}_{1}$ & \\
\hline \multirow{2}{*}{$\begin{array}{l}50 \text { melhores } \\
\text { (menor valor) }\end{array}$} & Verão & 0,84 & 444,6 & 521,9 & $64,9(14,6)^{*}$ \\
\hline & Inverno & 0,89 & 844,8 & 582,9 & $-233,1(-27,6)$ \\
\hline \multirow{2}{*}{$\begin{array}{l}50 \text { piores } \\
\text { (maior valor) }\end{array}$} & Verão & 0,84 & 444,6 & 351,5 & $-78,2(-17,6)$ \\
\hline & Inverno & 0,89 & 844,8 & $1.115,3$ & $240,7(28,5)$ \\
\hline \multirow{3}{*}{$\begin{array}{l}50 \text { melhores } \\
\text { (maior valor) }\end{array}$} & \multicolumn{5}{|c|}{ ITC $_{2}$} \\
\hline & Verão & 0,84 & 444,6 & 595,2 & $126,5(28,5)$ \\
\hline & Inverno & 0,89 & 844,8 & 836,8 & $-7,1(-0,8)$ \\
\hline \multirow{2}{*}{$\begin{array}{l}50 \text { piores } \\
\text { (menor valor) }\end{array}$} & Verão & 0,84 & 444,6 & 326,7 & $-99,0(-22,3)$ \\
\hline & Inverno & 0,89 & 844,8 & 833,8 & $-9,8(-1,2)$ \\
\hline
\end{tabular}

${ }^{(1)} \overline{\mathrm{X}}_{\mathrm{S}}$ : média das progênies selecionadas; $\overline{\mathrm{X}}_{\mathrm{O}}$ : média geral das progênies; $\mathrm{h}^{2}$ : herdabilidade do caráter; GS: ganho por seleção; valores entre parênteses referem-se aos ganhos porcentuais. 
neste ambiente. Porém, no ambiente de verão, resultou em $-22,3 \%$ de redução na produtividade média dessas progênies.

Esses resultados demonstram a superioridade do $\mathrm{ITC}_{2}$ sobre o ITC $_{1}$, na medida em que este maximiza a associação com as produtividades no ambiente de estresse e se mantém independente das produtividades sob condições favoráveis.

De fato, foi obtido para os valores de ITC $_{2}$ com as produtividades encontradas no ambiente com estresse (verão), coeficiente de correlação de 0,997 , ao passo que o valor desse coeficiente com as produtividades obtidas no ambiente considerado favorável (inverno) foi de 0,0 (Tabela 5). Em estudo realizado por Coelho (1995), também foi encontrada alta associação desse índice com as produtividades das progênies no ambiente de estresse e nenhuma com as produtividades em condição ótima de cultivo.

$\mathrm{O}$ valor do coeficiente de correlação obtido para a relação entre o ITC 1 e as produtividades alcançadas pelas progênies, em condições de estresse, foi de -0,588; este coeficiente assumiu o valor de 0,802 para a comparação com as produtividades obtidas na condição considerada ótima para o cultivo do trigo. Esses resultados estão de acordo com os encontrados por Yang et al. (2002), que utilizaram o índice ITC $_{1}$ e relatam a existência de associação positiva com a produtividade de grãos, no ambiente favorável, e negativa no ambiente de estresse.

$\mathrm{O}$ índice ITC $_{2}$ decompõe a produtividade das progênies em dois componentes. O primeiro é a produtividade comum aos dois ambientes, que é igualada a zero em todos os genótipos. O segundo é a produtividade que é específica para aquele ambiente sob o qual a seleção atua (Coelho, 1995). Esse índice pode ser definido para quaisquer condições ambientais, permitindo, portanto, a avaliação da aptidão dos diversos genótipos para cada condição específica de ambiente que se queira avaliar.

Tabela 5. Coeficientes de correlação de Pearson entre produtividade de grãos e índice de tolerância ao calor de 240 famílias de trigo cultivadas no inverno e verão.

\begin{tabular}{clc}
\hline Indice de tolerância ao calor & Época & Índice \\
\hline ITC $_{1}$ & Verão & $-0,588^{* *}$ \\
& Inverno & $0,802^{* *}$ \\
\hline ITC $_{2}$ & Verão & $0,997^{* *}$ \\
& Inverno & $0,000^{\mathrm{ns}}$ \\
\hline
\end{tabular}

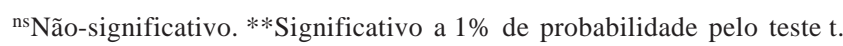

Segundo esta estratégia, o melhoramento nas condições de estresse atua para aprimorar o comportamento dos genótipos sobre determinadas condições específicas, não se alterando, concomitantemente, suas produtividades em outras condições menos restritas. Para Khanna-Chopra \& Viswanathan (1999), seria desejável combinar produtividade elevada com tolerância ao calor, de forma que as progênies pudessem ser utilizadas em ambas as condições de plantio, inverno e verão.

A forma pela qual o índice $\mathrm{ITC}_{2}$ é definido sugere que sua utilização em programas de melhoramento permitiria o incremento da produtividade sob condição específica, por meio da identificação de genótipos com adaptabilidade específica ao ambiente de estresse, sem alterar o comportamento desses genótipos em condições favoráveis. Isso possibilitaria diminuir o tempo para obtenção de resultados em programas de melhoramento para o Brasil Central, efetuando-se a seleção tanto na época de verão quanto no inverno.

\section{Conclusões}

1. Há participação dos efeitos de ambiente (época de semeadura) na expressão dos genótipos.

2. A porcentagem da interação de natureza complexa é maior que a de natureza simples e os ganhos com seleção indireta em um ambiente não são eficientes, principalmente quanto à produtividade de grãos.

3. O uso do índice de tolerância ao calor, com base na regressão, permite detectar genótipos melhor adaptados ao ambiente de estresse de calor, sem alterar o comportamento desses genótipos em condições favoráveis.

\section{Agradecimentos}

Ao CNPq e à Universidade Federal de Viçosa, pelo apoio.

\section{Referências}

BEARZOTI, E. Simulação de seleção recorrente assistida por marcadores moleculares em espécies autógamas. 1997. 230p. Tese (Doutorado) - Escola Superior de Agricultura Luiz de Queiroz, Piracicaba.

BORÉM, A. Melhoramento de plantas. Viçosa: UFV, 1997. 547p. CARVALHO, C.G.P. de; ARIAS, C.A.A.; TOLEDO, J.F.F. de; ALMEIDA, L.A. de; KIIHL, R.A. de S.; OLIVEIRA, M.F. de. Interação genótipo $\mathrm{x}$ ambiente no desempenho produtivo da 
soja no Paraná. Pesquisa Agropecuária Brasileira, v.37, p.989-1000, 2002.

COELHO, A.S.G. Critérios de seleção para tolerância ao déficit hídrico em uma população de milho (Zea mays L.). 1995. 77p. Dissertação (Mestrado) - Universidade Federal de Goiás, Goiânia.

COIMBRA, J.L.M.; GUIDOLIN, A.F.; CARVALHO, F.I.F.; COIMBRA, S.M.M.; HEMP, S. Reflexos da interação genótipo x ambiente e suas implicações nos ganhos de seleção em genótipos de feijão (Phaseolus vulgaris L.). Ciência Rural, v.29, p.433-439, 1999.

CRUZ, C.D. Programa GENES: versão Windows; aplicativo computacional em genética e estatística. Viçosa: UFV, 2001. 648p.

CRUZ, C.D.; CASTOLDI, F.L. Decomposição da interação genótipos $\mathrm{x}$ ambientes em partes simples e complexa. Revista Ceres, v.38, p.422-430, 1991.

CRUZ, C.D.; REGAZZI, A. Modelos biométricos aplicados ao melhoramento genético. Viçosa: UFV, 1997. 390p.

FALCONER, D.S.; MacKAY, T.F.C. Introduction to quantitative genetics. $4^{\text {th }}$ ed. London: Longman, 1996. 463p.

FISCHER, R.A.; MAUER, R. Drought resistance in spring wheat cultivars. I. Grain yield responses. Australian Journal of Agricultural Research, v.29, p.897-912, 1978.

KHANNA-CHOPRA, R.; VISWANATHAN, C. Evaluation of heat stress tolerance in irrigated environment of T. aestivum and related species. I. Stability in yield and yield components. Euphytica, v.106, p.169-180, 1999.

LÚCIO, A.D.; STORCK, L.; BANZATTO, D.A. Classificação dos experimentos de competição de cultivares quanto a sua precisão. Pesquisa Agropecuária Gaúcha, v.5, p.99-103, 1999.

RAMALHO, M.A.P.; SANTOS, J.B.; ZIMMERMANN, M.J.O. Genética quantitativa de plantas autógamas: aplicações ao melhoramento do feijoeiro. Goiânia: UFG, 1993. 271p.

REUNIÃO DA COMISSÃO CENTRO BRASILEIRA DE PESQUISA DE TRIGO, 12., 2002, Uberlândia. Indicações técnicas para a cultura de trigo na região do Brasil-Central: safra 2003 e 2004. Passo Fundo: Embrapa Transferência de Tecnologia; Escritório de Negócios do Triângulo Mineiro, 2003. 109p.

SOUZA, M.A. Controle genético e resposta ao estresse de calor de cultivares de trigo. 1999. 152p. Tese (Doutorado) - Universidade Federal de Lavras, Lavras.

SOUZA, M.A. de; RAMALHO, M.A.P. Controle genético e tolerância ao estresse de calor em populações híbridas e em cultivares de trigo. Pesquisa Agropecuária Brasileira, v.36, p.1245-1253, 2001.

YANG, J.; SEARS, R.G.; GILL, B.S.; PAULSEN, G.M. Growth and senescence characteristics associated with tolerance of wheat-alien amphiploids to high temperature under controlled conditions. Euphytica, v.126, p.185-193, 2002.

Recebido em 31 de março de 2005 e aprovado em 8 de dezembro de 2005 